\title{
Role of Advanced Glycation End Products and Its Receptors in the Pathogenesis of Cigarette Smoke-Induced Cardiovascular Disease
}

\author{
Kailash Prasad, MBBS (Hons.), MD, PhD, FRCPC, FACC, FICA, FIACS ${ }^{1}$ Indu Dhar, PhD² \\ Gudrun Caspar-Bell, MD, FRCPC ${ }^{3}$
}

${ }^{1}$ Department of Physiology, College of Medicine, University of Saskatchewan, Saskatoon, Canada

${ }^{2}$ Department of Pharmacology, College of Medicine, University of Saskatchewan, Saskatoon, Canada

${ }^{3}$ Department of Medicine, Royal University Hospital, College of Medicine, University of Saskatchewan, Saskatoon, Canada

\begin{abstract}
Address for correspondence Kailash Prasad, MBBS (Hons.), MD, PhD, FRCPC, FACC, FICA, FIACS, Department of Physiology, College of Medicine, University of Saskatchewan, 107 Wiggins Road, Saskatoon, SK, S7N 5E5, Canada (e-mail: k.prasad@usask.ca).
\end{abstract}

Int J Angiol 2015;24:75-80.

\begin{abstract}
The interaction of advanced glycation end products (AGEs) with its cell-bound receptor RAGE increases gene expression and release of proinflammatory cytokines and increase generation of reactive oxygen species (ROS). Circulating receptors, soluble RAGE (sRAGE), and endosecretory RAGE (esRAGE) by binding with RAGE ligands have protective effects against AGE-RAGE interaction. Cigarette smoking is a risk factor for coronary artery disease, stroke, and peripheral vascular disease. This article reviews; if the AGE-RAGE axis is involved in the cigarette smoke-induced cardiovascular diseases. There are various sources of AGEs in smokers including, gas/tar of cigarette, activation of macrophages and polymorphonuclear leukocytes, uncoupling of endothelial isoform of nitric oxide synthase (eNOS) and xanthine oxidase. The levels of AGEs are elevated in smokers. Serum levels of sRAGE have been reported to be reduced, elevated, or unchanged in smokers. Mostly the levels are reduced. There is one article which shows an elevation of levels of sRAGE in smokers. Serum levels of esRAGE are unaltered in

\section{Keywords}

- cigarette smokers

- advanced glycation end products

- soluble receptors for AGES

- receptor for $\mathrm{AGE}$

- cardiovascular disease smokers. Mechanism of AGE-RAGE-induced atherosclerosis has been discussed. Atherosclerosis leads to the cardiovascular diseases. It has been suggested that ratio of AGE/ sRAGE or AGE/esRAGE is useful in determining the deleterious effects of AGE-RAGE interaction in smokers. sRAGE alone is not a good marker for smoke-induced cardiovascular disease. In conclusion cigarette smoke induces formation of AGEs and reduces sRAGE resulting in the development of atherosclerosis and related coronary heart disease, stroke, and peripheral vascular disease. Ratio of AGEs/sRAGE is a better marker for cardiovascular disease than AGEs or sRAGE alone in smokers.
\end{abstract}

Cigarette smoking is a major risk factor for coronary artery disease (CAD), stroke, and peripheral vascular disease., ${ }^{1,2}$ Smoking predisposes to aortic and peripheral atherosclerosis resulting in abdominal aortic aneurysm and intermitted claudication. ${ }^{3}$ Epidemiological studies show that cigarette smokers have greater risk of developing CAD than nonsmokers. $^{3-7}$

Coronary angiography in severe cigarette smokers has shown that the coronary arteries are atherosclerosed. ${ }^{8}$ Cigarette smoking is an independent predictor of new coronary published online

December 12, 2014
Copyright $\odot 2015$ by Thieme Medical Publishers, Inc., 333 Seventh Avenue, New York, NY 10001, USA. Tel: +1(212) 584-4662.
DOI http://dx.doi.org/ 10.1055/s-0034-1396413. ISSN 1061-1711. 
lesion. ${ }^{9}$ The mechanisms of cigarette-induced cardiovascular diseases are numerous including, atherosclerosis, ${ }^{10}$ thrombosis, ${ }^{11}$ and coronary spasm. ${ }^{12}$ Oxidative stress has been implicated in the development of atherosclerosis. ${ }^{13,14}$ Cigarette smoking may induce atherosclerosis through reactive oxygen species (ROS). Cigarette smoking could generate ROS through gas/tar of cigarette, activation of macrophage and polymorphonuclear leukocytes, uncoupling endothelial isoform of NOS, and xanthine oxidase. ${ }^{15-21}$

Advanced glycation end products (AGEs) and its receptor, soluble receptors for AGEs (sRAGE) have been implicated in the cardiovascular diseases. It has been reported that the serum levels of sRAGE are low ${ }^{22-26}$ while the levels of AGEs are high ${ }^{25,27}$ in patients with nondiabetic CAD. In animal studies it has been shown that AGE-RAGE axis is implicated in the development of atherosclerosis. ${ }^{28-30}$

Interaction of AGEs with its cellular receptor, receptor for AGEs (RAGE) produces ROS. ${ }^{31,32}$ The sRAGE, the other receptors for AGEs acts as a decoy for RAGE ligands (AGEs) and compete with membrane-bound RAGE for ligand binding and thus reduce the generation of ROS.

It is possible that low serum levels of sRAGE and high levels of AGEs are involved in the cigarette smoke-induced cardiovascular diseases.

The present review deals with the AGEs-RAGE axis, sources of AGEs in smokers, serum levels of AGEs, sRAGE and esRAGE in smokers, and mechanism of atherosclerosis.

\section{AGEs-RAGE Axis}

AGEs are heterogeneous group of irreversible adducts resulting from the nonenzymatic glycation and glycoxidation of proteins, nucleic acid, and lipids. ${ }^{33}$ Glucose interacts with free amino group of lysine or arginine, producing Schiff bases, which are rapidly transformed into Amadori products. A series of complex reactions results in the formation of AGEs including Né-carboxymethyl-lysine, Né-carboxyethyl-lysine, pentosidine, furosine, and pyraline. There are four receptors for AGEs: full length RAGE, a member of the immunoglobulin super family and is multiligand receptor; N-truncated RAGE, C-terminal RAGE having two isoforms, cRAGE (cleaved RAGE) and esRAGE. cRAGE is proteolytically cleaved from cell surface $^{34}$ while esRAGE is alternative splicing to remove the transmembrane region. ${ }^{35}$ Both esRAGE and cRAGE are extracellular and functionally equivalent and interact with the same RAGE ligands. Measurement of total sRAGE includes both cRAGE and esRAGE (sRAGE enzyme-linked immunosorbent assay kit) while measurement of esRAGE measures only esRAGE which is about $20 \%$ of the total sRAGE. $^{36}$

Interaction of AGEs with full length RAGE activates nuclear factor карра-B (NF-кB), increases gene expression and release of inflammatory cytokines, and increases production of ROS. $31,32,37$

Both SRAGE and esRAGE act as a decoy for RAGE by binding with RAGE ligands and preventing them from binding with membrane-bound full length RAGE. ${ }^{34}$ sRAGE and esRAGE have protective effects against AGE-RAGE interaction.

\section{Sources of AGEs in Smokers}

The information related to the sources of AGEs in smokers is very few. Cerami et $\mathrm{al}^{38}$ did an extensive study on the formation of AGEs from tobacco leaves and cigarette smoke. They reported that reactive glycation products (glycotoxins) are present in the water extracts of tobacco leaves and tobacco smoke promote formation of AGEs in vivo and in vitro. The generation of AGEs by cigarette smoke was concentration and time dependent. They also showed that cigarette smoke condensate was approximately 10 -fold less active in production of AGEs than aqueous tobacco leave extracts. The AGEs-forming activity is extremely labile in both cases. The glycotoxins are highly reactive and can induce AGEs formation in hours. The AGEs formation with glucose or glucose-6phosphate takes days to weeks. Glycotoxins from cigarette are inhaled into lung alveoli and then transformed to blood stream or lung cells where they can interact with other glycation products and contribute to the formation of AGEs. Nicholl and Bucala ${ }^{39}$ proposed that certain components of cigarette smoke can interact with plasma and extracellular matrix proteins to form covalent adducts with many properties of AGEs. The data suggest that cigarette smoke can produce AGEs.

\section{Serum Levels of AGEs}

Serum levels of AGEs are elevated in cigarette smokers. ${ }^{39}$ Radoi et $\mathrm{al}^{40}$ reported that during smoking, the combustion of pre-AGE compounds present in tobacco produces a series of reactive and toxic AGE. AGE or LDL-linked AGE levels in serum are elevated in cigarette smokers. In another study, Berg et $\mathrm{al}^{41}$ have shown that current or past smokers have increased serum levels of AGEs compared with those who never smoked, median levels of AGEs were $10.7 \mathrm{U} / \mathrm{mL}$ (range, 7.8-16.5 U/mL) and 9.5 U/mL (range, 7.1-13.8 U/mL) (smokers vs. nonsmokers).

AGEs levels are not only elevated in the serum but also in the tissue. Nicholl et $\mathrm{al}^{42}$ have shown that the levels of AGEs or immunologically related molecules are higher in the lenses and blood vessels of cigarette smokers. These data suggest that serum and tissue levels of AGEs are elevated in cigarette smokers.

\section{Serum Levels of SRAGE and esRAGE in Smokers}

The serum levels of sRAGE in smokers are variable. There are various reports which show a decrease in serum levels of sRAGE in smokers. Gopal et $\mathrm{al}^{43}$ reported that plasma levels of sRAGE were lower in ex-smokers as compared with the never smokers. In patients with chronic obstructive pulmonary disease (COPD) the sRAGE levels were not significantly different between ex-smokers and current smokers. ${ }^{43}$ However, Iwamoto et $\mathrm{al}^{44}$ reported that the plasma levels of sRAGE are lower in smokers with COPD $(969.1 \pm 406.0 \mathrm{pg} / \mathrm{mL})$ and smokers without COPD $(973.4 \pm 426.5 \mathrm{pg} / \mathrm{mL})$ as compared with nonsmokers $(1,201.1 \pm 483.6 \mathrm{pg} / \mathrm{mL})$. Reduction of 
serum SRAGE in smokers has been also reported by Yokota et al. ${ }^{45}$ On the contrary to the above reports, Biswas et al ${ }^{46}$ showed an elevated level of serum sRAGE in smokers. The levels were elevated in nondiabetic healthy cigarette smokers $(1,475 \pm 422 \mathrm{pg} / \mathrm{mL})$ as compared with nonsmokers $(1,165 \pm 350 \mathrm{pg} / \mathrm{mL})$. Serum sRAGE were significantly correlated with number of cigarette smoked per day. Serum sRAGE was positively correlated with the smoking habit. The levels of serum sRAGE were not significantly different between healthy control subjects and healthy smokers. ${ }^{47}$

The serum levels of esRAGE were not significantly different between never smokers and ex-smokers, and between exsmoker and current smokers. ${ }^{43}$ The data suggest that serum levels of sRAGE are low, high, or unaltered in cigarette smokers. The levels of esRAGE are not affected by cigarette smoke.

\section{Mechanism of AGEs-RAGE Axis-Induced Atherosclerosis}

Interaction of AGEs with full length RAGE increases production of ROS, activates NF- $\mathrm{KB}$ and increases the expression of adhesion molecules and cytokines. ${ }^{31,32,37}$ Cytokines are known to stimulate granulocytes to generate ROS. ${ }^{48-51}$

ROS have been implicated in the development of atherosclerosis. ${ }^{13,52}$ Oxidative hypothesis of atherosclerosis has been detailed elsewhere. ${ }^{53}$ In short low-density lipoprotein (LDL) cholesterol is mildly oxidized to minimally modified LDL (MM-LDL) which stimulates smooth muscle cells and endothelial cells to produce monocyte chemoattractant protein-1 (MCP-1). ROS increases the expression of cell adhesion molecules, intercellular adhesion molecule-1, vascular cell adhesion molecule-1, and endothelial leukocyte adhesion molecules on the endothelial cells. ${ }^{54-57}$ Cell adhesion molecules help monocytes to adhere to the endothelial cell surface. MM-LDL is further oxidized to oxidized-LDL (OX-LDL). MCP-1 and OX-LDL facilitate the migration of monocyte to migrate to the subendothelial area. MM-LDL induces release of monocyte colony stimulating factor from endothelial cells that help in differentiation of monocyte/ macrophage. Differentiated macrophage develops receptor for OX-LDL which is taken up by macrophage to form foam cells. Macrophage increases the expression of numerous growth factors which leads to the formation of collagen, elastic fiber, and protein and transcription of smooth muscle cells. Proliferation and migration of smooth muscle cells, synthesis of connective tissue and matrix, migration of monocyte and formation of foam cells, culminate in the initiation and progression of atherosclerosis. The role of AGEs-RAGE interaction in the development of atherosclerosis and the protective effects of SRAGE and esRAGE are depicted in - Fig. 1.

Interaction of AGE and RAGE will produce atherosclerosis. SRAGE and esRAGE interacts with AGEs and hence fewer AGEs are available to interact with RAGE resulting in the reduced production of ROS, cytokines, and cell adhesion molecules. This will result in attenuation of the formation of atherosclerosis.

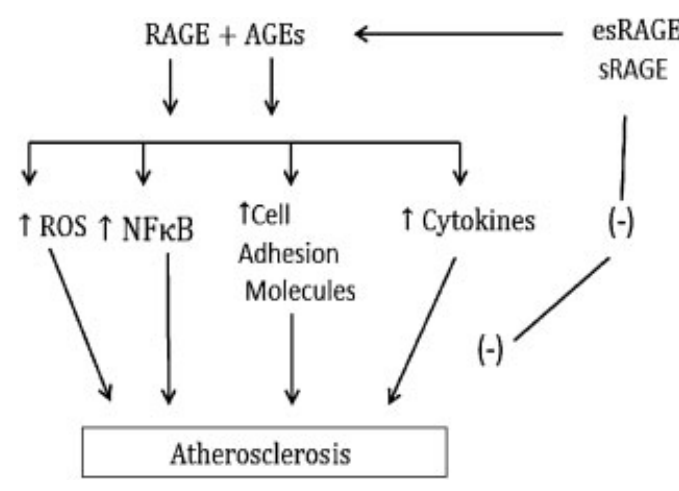

Fig. 1 Figure shows the role of the interaction of AGEs and RAGE in the development of atherosclerosis and protective effects of SRAGE and esRAGE against AGE and RAGE-induced atherosclerosis. (-), decrease; $\uparrow$, increase; AGEs, advanced glycation end products; esRAGE, endogenous secretory RAGE; NF-kB, nuclear factor-kappa B; RAGE, receptor for AGEs; ROS, reactive oxygen species; sRAGE, soluble receptor for RAGE.

\section{Comments}

Most of the published data show that there is a reduction in the serum levels of sRAGE in cigarette smokers ${ }^{43-45}$ except one report which shows an increase in the serum levels of sRAGE in smokers. ${ }^{46}$ It is very difficult to reconcile these differences in the serums levels of RAGE in smokers. There are numerous data which suggest a protective role of sRAGE against deleterious effects of AGE-RAGE interaction ${ }^{22-26}$ in patients with nondiabetic CAD. AGE-RAGE axis has been implicated in the development of atherosclerosis in animals and SRAGE has been reported to have protective effects against atherosclerosis. ${ }^{28-30}$ As mentioned in the AGERAGE axis section of this review, interaction of AGE with RAGE increases the production of inflammatory cytokines, ROS and NF-KB which in turn induces proinflammatory cytokines. ${ }^{31,32,37}$ Low levels of sRAGE would increase the proinflammatory cytokines while high levels of sRAGE would reduce the proinflammatory cytokines. Biswas et al ${ }^{46}$ however reports that serum levels of sRAGE are elevated in smokers. They suggest that elevated levels of SRAGE would increase proinflammatory biomarkers and are responsible for cardiovascular disease in smokers.

Other investigators ${ }^{58,59}$ besides Biswas et $\mathrm{al}^{46}$ have suggested sRAGE a proinflammatory biomarker. Nakamura et $\mathrm{al}^{58}$ have shown that there is significant positive correlation between sRAGE and inflammatory markers in patients with type 2 diabetes. Pullerits et al ${ }^{59}$ have reported that SRAGE may be a proinflammatory and chemotactic molecule through its interaction with $\beta 2$ integrin Mac-1. However, these increases in the sRAGE may not be the culprit and proinflammatory biomarkers. These investigators did not measure the serum levels of AGEs in the studies.

Four players including, AGEs, cellular receptor RAGE, and circulating receptors SRAGE and esRAGE are involved in the AGE-RAGE axis. In humans it is not feasible to measure cellbound receptor RAGE. 
AGEs, SRAGE, and esRAGE can be measured in the serum of humans. Other players such as AGEs besides sRAGE and esRAGE should be considered in the equation of biomarker for disease associated with AGE-RAGE axis. Increases in serum sRAGE may be associated with increase in serum AGEs. If this occurs then increases in SRAGE may not be proinflammatory. If the increase in AGEs is more than SRAGE, more RAGE is available to interact with cell-bound RAGE to produce inflammatory mediators and ROS. For example, the levels of sRAGE are elevated in diabetes ${ }^{60-62}$ and end-stage renal disease. ${ }^{63,64}$ The levels of AGEs are also elevated in diabetes ${ }^{65-67}$ and end-stage renal disease. ${ }^{68,69}$ In this context, the authors would like to point out that the serum levels of AGEs are elevated in smokers. ${ }^{39-41}$ It is possible that elevated levels of serum sRAGE are not enough to handle large amount of AGEs. It would be scientifically sound to use the ratio of AGEs/sRAGE or AGEs/esRAGE as a biomarker of the disease. The statement of Biswas et al, ${ }^{46}$ that sRAGE is proinflammatory, does not seem scientifically sound. In this respect Prasad et $\mathrm{al}^{70}$ has reported that AGEs/sRAGE or AGEs/esRAGE would be a better biomarker than SRAGE or esRAGE for disease associated with AGE-RAGE axis.

In conclusion serum levels of sRAGE are low and the levels of AGE are elevated in cigarette smokers. The decrease in the serum levels of sRAGE and increase in the levels of AGEs may be involved in the cigarette smoke-induced cardiovascular disease in cigarette smokers. AGEs/sRAGE would be better proinflammatory marker than sRAGE or AGEs alone.

\section{Acknowledgment}

The authors acknowledge the assistance of Mr. Muhammad A. Shoker in preparation of the article.

\section{References}

1 Ockene IS, Miller NH; American Heart Association Task Force on Risk Reduction. Cigarette smoking, cardiovascular disease, and stroke: a statement for healthcare professionals from the American Heart Association. Circulation 1997;96(9):3243-3247

2 Price JF, Mowbray PI, Lee AJ, Rumley A, Lowe GD, Fowkes FG. Relationship between smoking and cardiovascular risk factors in the development of peripheral arterial disease and coronary artery disease: Edinburgh Artery Study. Eur Heart J 1999;20(5): 344-353

3 Black HR. Smoking and cardiovascular disease. In: Laragh JH, Brenner BM, eds. Hypertension: Pathophysiology, Diagnosis and management. 2nd ed. New York, NY: Raven Press Ltd; 1995: 2621-2647

4 Ambrose JA, Barua RS. The pathophysiology of cigarette smoking and cardiovascular disease: an update. J Am Coll Cardiol 2004; 43(10):1731-1737

5 Negri E, Franzosi MG, La Vecchia C, Santoro L, Nobili A, Tognoni G; GISSI-EFRIM Investigators. Tar yield of cigarettes and risk of acute myocardial infarction. BMJ 1993;306(6892):1567-1570

6 Jonas MA, Oates JA, Ockene JK, Hennekens CH; American Heart Association. Statement on smoking and cardiovascular disease for health care professionals. Circulation 1992;86(5):1664-1669

7 Barnoya J, Glantz SA. Cardiovascular effects of secondhand smoke: nearly as large as smoking. Circulation 2005;111(20):2684-2698
8 Herbert WH. Cigarette smoking and arteriographically demonstrable coronary artery disease. Chest 1975;67(1):49-52

9 Waters D, Lespérance J, Gladstone P, et al; CCAIT Study Group. Effects of cigarette smoking on the angiographic evolution of coronary atherosclerosis. A Canadian Coronary Atherosclerosis Intervention Trial (CCAIT) Substudy. Circulation 1996;94(4): 614-621

10 Office of the Surgeon General (US), Office on Smoking and Health (US). The Health Consequences of Smoking: A Report of the Surgeon General. Atlanta, GA: Centers for Disease Control and Prevention. Circulation 2005;111(20):2684-2698

11 Benowitz NL. Cigarette smoking and cardiovascular disease: pathophysiology and implications for treatment. Prog Cardiovasc Dis 2003;46(1):91-111

12 U.S Department of Health and Human Services. The Health benefits of Smoking cessation: A Report of the Surgeon General, DHHS Publication No. (CDC) 90-8416. Rockville, MD: U.S Department of Health and Human Services, Public health Services, Centers for Disease Control and Prevention; 1990

13 Prasad K. Reduction of serum cholesterol and hypercholesterolemic atherosclerosis in rabbits by secoisolariciresinol diglucoside isolated from flaxseed. Circulation 1999;99(10):1355-1362

14 Prasad K, Lee P. Suppression of hypercholesterolemic atherosclerosis by pentoxifylline and its mechanism. Atherosclerosis 2007; 192(2):313-322

15 Pryor WA, Stone K. Oxidants in cigarette smoke. Radicals, hydrogen peroxide, peroxynitrate, and peroxynitrite. Ann N Y Acad Sci 1993;686:12-27, discussion 27-28

16 Smith CJ, Fischer TH. Particulate and vapor phase constituents of cigarette mainstream smoke and risk of myocardial infarction. Atherosclerosis 2001;158(2):257-267

17 Barua RS, Ambrose JA, Srivastava S, DeVoe MC, Eales-Reynolds LJ. Reactive oxygen species are involved in smoking-induced dysfunction of nitric oxide biosynthesis and upregulation of endothelial nitric oxide synthase: an in vitro demonstration in human coronary artery endothelial cells. Circulation 2003;107(18): 2342-2347

18 Srivastava SK, Barua RS, Saha DC, Eales-Reynolds LJ, DeVoe MC, Ambrose JA. Endogenous free radical generating source are involved in smoking-mediated dysfunction of nitric oxide biosynthesis in human coronary artery endothelial cells: an in vitro demonstration. (abstr). J Am Coll Cardiol 2003;41(Suppl A)306A

19 Kayyali US, Budhiraja R, Pennella CM, et al. Upregulation of xanthine oxidase by tobacco smoke condensate in pulmonary endothelial cells. Toxicol Appl Pharmacol 2003;188(1):59-68

20 Guthikonda S, Sinkey C, Barenz T, Haynes WG. Xanthine oxidase inhibition reverses endothelial dysfunction in heavy smokers. Circulation 2003;107(3):416-421

21 Kalra J, Chaudhary AK, Prasad K. Increased production of oxygen free radicals in cigarette smokers. Int J Exp Pathol 1991;72(1):1-7

22 Falcone C, Emanuele E, D’Angelo A, et al. Plasma levels of soluble receptor for advanced glycation end products and coronary artery disease in nondiabetic men. Arterioscler Thromb Vasc Biol 2005; 25(5):1032-1037

23 Lindsey JB, de Lemos JA, Cipollone F, et al. Association between circulating soluble receptor for advanced glycation end products and atherosclerosis: observations from the Dallas Heart Study. Diabetes Care 2009;32(7):1218-1220

24 Hudson BI, Moon YP, Kalea AZ, et al. Association of serum soluble receptor for advanced glycation end-products with subclinical cerebrovascular disease: the Northern Manhattan Study (NOMAS). Atherosclerosis 2011;216(1):192-198

25 McNair ED, Wells CR, Qureshi AM, et al. Low levels of soluble receptor for advanced glycation end products in non-ST elevation myocardial infarction patients. Int J Angiol 2009;18(4):187-192

26 McNair ED, Wells CR, Mabood Qureshi A, et al. Soluble receptors for advanced glycation end products (sRAGE) as a predictor of 
restenosis following percutaneous coronary intervention. Clin Cardiol 2010;33(11):678-685

27 Basta G, Berti S, Cocci F, et al. Plasma N-epsilon-(carboxymethyl) lysine levels are associated with the extent of vessel injury after coronary arterial stenting. Coron Artery Dis 2008;19(5):299-305

28 Park L, Raman KG, Lee KJ, et al. Suppression of accelerated diabetic atherosclerosis by the soluble receptor for advanced glycation endproducts. Nat Med 1998;4(9):1025-1031

29 Sakaguchi T, Yan SF, Yan SD, et al. Central role of RAGE-dependent neointimal expansion in arterial restenosis. J Clin Invest 2003; 111(7):959-972

30 Bucciarelli LG, Wendt T, Qu W, et al. RAGE blockade stabilizes established atherosclerosis in diabetic apolipoprotein E-null mice. Circulation 2002;106(22):2827-2835

31 Prasad K. Soluble receptor for advanced glycation end products (sRAGE) and cardiovascular disease. Int J Angiol 2006;15:57-68

32 Schmidt AM, Yan SD, Yan SF, Stern DM. The biology of the receptor for advanced glycation end products and its ligands. Biochim Biophys Acta 2000;1498(2-3):99-111

33 Bierhaus A, Hofmann MA, Ziegler R, Nawroth PP. AGEs and their interaction with AGE-receptors in vascular disease and diabetes mellitus. I. The AGE concept. Cardiovasc Res 1998;37(3):586-600

34 Tam XHL, Shiu SWM, Leng L, Bucala R, Betteridge DJ, Tan KCB. Enhanced expression of receptor for advanced glycation endproducts is associated with low circulating soluble isoforms of the receptor in Type 2 diabetes. Clin Sci (Lond) 2011;120(2):81-89

35 Yonekura H, Yamamoto Y, Sakurai S, et al. Novel splice variants of the receptor for advanced glycation end-products expressed in human vascular endothelial cells and pericytes, and their putative roles in diabetes-induced vascular injury. Biochem J 2003;370(Pt 3):1097-1109

36 Koyama H, Shoji T, Yokoyama H, et al. Plasma level of endogenous secretory RAGE is associated with components of the metabolic syndrome and atherosclerosis. Arterioscler Thromb Vasc Biol 2005;25(12):2587-2593

37 Schmidt AM, Yan SD, Wautier JL, Stern D. Activation of receptor for advanced glycation end products: a mechanism for chronic vascular dysfunction in diabetic vasculopathy and atherosclerosis. Circ Res 1999;84(5):489-497

38 Cerami C, Founds H, Nicholl I, et al. Tobacco smoke is a source of toxic reactive glycation products. Proc Natl Acad Sci U S A 1997; 94(25):13915-13920

39 Nicholl ID, Bucala R. Advanced glycation endproducts and cigarette smoking. Cell Mol Biol (Noisy-le-grand) 1998;44(7):1025-1033

40 Radoi V, Lixandru D, Mohora M, Vîrgolici B. Advanced glycation end products in diabetes mellitus: mechanism of action and focused treatment. Proc Rom Acad, Series B. 2012;1:9-19

41 Berg TJ, Snorgaard O, Faber J, et al. Serum levels of advanced glycation end products are associated with left ventricular diastolic function in patients with type 1 diabetes. Diabetes Care 1999;22(7):1186-1190

42 Nicholl ID, Stitt AW, Moore JE, Ritchie AJ, Archer DB, Bucala R. Increased levels of advanced glycation endproducts in the lenses and blood vessels of cigarette smokers. Mol Med 1998;4(9): 594-601

43 Gopal P, Reynaert NL, Scheijen JL, et al. Association of plasma sRAGE, but not esRAGE with lung function impairment in COPD. Respir Res 2014;15:24

44 Iwamoto H, Gao J, Pulkkinen V, Toljamo T, Nieminen P, Mazur W. Soluble receptor for advanced glycation end-products and progression of airway disease. BMC Pulm Med 2014;14:68

45 Yokota C, Minematsu K, Tomii Y, et al. Low levels of plasma soluble receptor for advanced glycation end products are associated with severe leukoaraiosis in acute stroke patients. J Neurol Sci 2009; 287(1-2):41-44

46 Biswas SK, Mudi SR, Mollah FH, Bierhaus A, Arslan MI. Serum soluble receptor for advanced glycation end products (sRAGE) is independently associated with cigarette smoking in non-diabetic healthy subjects. Diab Vasc Dis Res 2013;10(4):380-382

47 Smith DJ, Yerkovich ST, Towers MA, Carroll ML, Thomas R, Upham JW. Reduced soluble receptor for advanced glycation end-products in COPD. Eur Respir J 2011;37(3):516-522

48 Braquet P, Hosford D, Braquet M, Bourgain R, Bussolino F. Role of cytokines and platelet-activating factor in microvascular immune injury. Int Arch Allergy Appl Immunol 1989;88(1-2): 88-100

49 Yuo A, Kitagawa S, Kasahara T, Matsushima K, Saito M, Takaku F. Stimulation and priming of human neutrophils by interleukin-8: cooperation with tumor necrosis factor and colony-stimulating factors. Blood 1991;78(10):2708-2714

50 Ellis TN, Beaman BL. Interferon-gamma activation of polymorphonuclear neutrophil function. Immunology 2004;112(1):2-12

51 Watson DA, Musher DM, Hamill RJ. Interferon-gamma and polymorphonuclear leukocytes. Ann Intern Med 1988;109(3): 250-251

52 Steinberg D. Antioxidants and atherosclerosis. A current assessment. Circulation 1991;84(3):1420-1425

53 Prasad K. Textbook of Angiology. In: John B Chang, Earl R Olsen, Kailash Prasad, Bauer E Sumpio, eds. Pathophysiology of Atherosclerosis. New York, NY: Springer-Verlag; 2000:85-105

54 Martin A, Foxall T, Blumberg JB, Meydani M. Vitamin E inhibits low-density lipoprotein-induced adhesion of monocytes to human aortic endothelial cells in vitro. Arterioscler Thromb Vasc Biol 1997;17(3):429-436

55 Faruqi R, de la Motte C, DiCorleto PE. Alpha-tocopherol inhibits agonist-induced monocytic cell adhesion to cultured human endothelial cells. J Clin Invest 1994;94(2):592-600

56 Devaraj S, Li D, Jialal I. The effects of alpha tocopherol supplementation on monocyte function. Decreased lipid oxidation, interleukin 1 beta secretion, and monocyte adhesion to endothelium. J Clin Invest 1996;98(3):756-763

57 Keaney JF Jr, Gaziano JM, Xu A, et al. Low-dose alpha-tocopherol improves and high-dose alpha-tocopherol worsens endothelial vasodilator function in cholesterol-fed rabbits. J Clin Invest 1994; 93(2):844-851

58 Nakamura K, Yamagishi S, Adachi H, et al. Serum levels of sRAGE, the soluble form of receptor for advanced glycation end products, are associated with inflammatory markers in patients with type 2 diabetes. Mol Med 2007;13(3-4):185-189

59 Pullerits R, Brisslert M, Jonsson IM, Tarkowski A. Soluble receptor for advanced glycation end products triggers a proinflammatory cytokine cascade via beta2 integrin Mac-1. Arthritis Rheum 2006; 54(12):3898-3907

60 Fujisawa K, Katakami N, Kaneto H, et al. Circulating soluble RAGE as a predictive biomarker of cardiovascular event risk in patients with type 2 diabetes. Atherosclerosis 2013;227(2): 425-428

61 Tan KCB, Shiu SWM, Chow WS, Leng L, Bucala R, Betteridge DJ. Association between serum levels of soluble receptor for advanced glycation end products and circulating advanced glycation end products in type 2 diabetes. Diabetologia 2006;49(11): 2756-2762

62 Challier M, Jacqueminet S, Benabdesselam O, Grimaldi A, Beaudeux JL. Increased serum concentrations of soluble receptor for advanced glycation endproducts in patients with type 1 diabetes. Clin Chem 2005;51(9):1749-1750

63 Basta G, Leonardis D, Mallamaci F, et al. Circulating soluble receptor of advanced glycation end product inversely correlates with atherosclerosis in patients with chronic kidney disease. Kidney Int 2010;77(3):225-231

64 Hammady MR, Khashali SEL, Halim HA, Rashed L, Hussein M. Soluble receptor for advanced glycation end products (SRAGE) in non-diabetic hemodialysis patients and chronic kidney disease. Med J Cairo Univ 2012;80:9-75 
65 Tan KC, Chow WS, Tam S, Bucala R, Betteridge J. Association between acute-phase reactants and advanced glycation end products in type 2 diabetes. Diabetes Care 2004;27(1):223-228

66 Berg TJ, Dahl-Jørgensen K, Torjesen PA, Hanssen KF. Increased serum levels of advanced glycation end products (AGEs) in children and adolescents with IDDM. Diabetes Care 1997;20(6):1006-1008

67 Kilhovd BK, Berg TJ, Birkeland KI, Thorsby P, Hanssen KF. Serum levels of advanced glycation end products are increased in patients with type 2 diabetes and coronary heart disease. Diabetes Care 1999;22(9):1543-1548
68 Raj DS, Choudhury D, Welbourne TC, Levi M. Advanced glycation end products: a Nephrologist's perspective. Am J Kidney Dis 2000; 35(3):365-380

69 Papanastasiou P, Grass L, Rodela H, Patrikarea A, Oreopoulos D, Diamandis EP. Immunological quantification of advanced glycosylation end-products in the serum of patients on hemodialysis or CAPD. Kidney Int 1994;46(1):216-222

70 Prasad K. Low levels of serum soluble receptors for advanced glycation end products, biomarkers for disease states: Myth or reality. Int J Angiol 2014;23:11-16 